\title{
Surotul Mar ati al-Ijabiyah fi Al-Amsal al-Arabiyati Wa al-Amsali al-Swahiliyah (Dirosah Muqoronah)
}

\section{صورة المرأة الإيجابية في الأمثال العربية والأمثال السواحلية (دراسة مقارنة)}

\section{Faisal Masuod Muhindo}

faisud@yahoo.com

Department of Arabic language and literature

King Saud University, Kingdom of Saudi Arabia

• Received: 06.05.2020 • Accepted: 21.10.2020 • Published online: 24.11 .2020

Abstract: This study aimed to reveal the image of women in Arabic and Swahili Proverbs, and to identify the issues and meanings addressed by the owners of the environment in which the proverbs were said and broadcasted, in addition to highlighting the sweetness felt in the proverbs of humor and anagrams, which enhances literary pleasure. The research methodology used for this study was the comparative approach whereby an image of women was presented through Arabic and Swahili proverbs, and the researcher also used the descriptive analytical approach to highlight the contents of proverbs and their significance to reveal the image of women that reflects their status in society, and this enabled the researcher in comparing the image of omen between Arabic and Swahili proverbs. The results of the research indicated that there are proverbs in Arabic and Swahili languages that glorifies women and raises their status which are few when compared to other proverbs that detract their status and reduce their value, we sometimes find that the two extremes coexist in one example.

Keywords: Image of woman, Arabic, proverb Text, Swahili

$$
\begin{aligned}
& \text { الملخص: تهدف هذه الدراسة إلى الكشف عن صورة المرأة بين الأمثال العربية والأمثال } \\
& \text { السواحلية والوقوف على القضايا والمعاني التي يتناولها أصحاب البيئة التي قيلت وذاعت فيها } \\
& \text { الأمثال، فضلاً عن إبراز العذوبة المحسوسة في الأمثال من فكاهة وجناس مما يعزز المتعة } \\
& \text { الأدبية. وكان منهج البحث المسخدم لهذه الدراسة هو المنهج المقارن، إذ به تمت تقديم }
\end{aligned}
$$


Faisal Masuod Muhindo

صورة عن المرأة من خلال الأمثال العربية والأمثال السواحلية، كما استعان الباحث بالمنهج الوصفي التحليلي لتسليط الضوء على مضامين الأمثال ودلالتها للكشف عن صورة المرأة التي تعكس وضعها في المجتمع، وهذا مكن الباحث من قيام بمقارنة صورة المرأة بين الأمثال العربية والأمثال السواحلية. وكانت نتائج البحث تشير إلى وجود أمثال في اللغة العربية واللغة

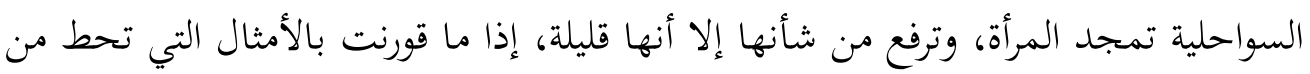
مكانتها وتقلل من قيمتها، حتى إننا نجد أحياناً تعايش النقيضين في مثل واحد. كلمات دلالية: صورة المرأة، المقارنة، الأمثال، السواحيلية

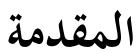

تعدُّ الأمثال تردد خلاصة التجربة اليومية التي صارت ملكا لمجموعة اجتماعياً معينة التي صارت جزءاً لا ينفصل عن سلوكها في حياتها اليومية الجارية، ومن أبرز عناصر الثقافة الشعبية؛ لأنها تحتل حجر الزاوية في معرفة الشعوب. فهي الصورة المعبرة لطبيعة الناس وتصوراتهم ومعتقداتهم وتناقضاتهم، بل إن لها شأناً خطيراً، مثلها في ذلك مثل بقية عناصر الثقافة الشعبية، في تشكيل أنماط اتجاهاتهم، وقيمهم، وسلوكهم الشائع في المجتمع. وهي تتغلغل في معظم جوانب الحياة الإنسانية، عاكسة خبرات الإنسان السابقة وتجاربهم ومواقفهم الحياتية المختلفة، بل إنها أحياناً ما تكون بمنزلة موجهات للسلوك حينما تقدم لهم نموذجا يقتدى به في الموافق المختلفة، وتصاغ في كلمات موجزة ذات طابع تعليمي وبأسلوب شعبي يسمو على الكلام اليومي الاعتيادي، مما يسهل حفظها وتداولها من جيل إلى جيل، والاستشهاد بها وقت الحاجة.(Majdi, 2009) وتكمن خصوصية الأمثال بوصفها مرآة صادقة تعكس صورة الجماعة المعبرة عنها، إلا أن هذه السمة لا تحول دون اتسامها بالعمومية، بمعنى أن الأمثال قد تختلف أو تتباين للتعبير عن طابعها المحلي الخاص، فقد نجدها تتماثل وتتشابه، وهي حقيقة مضمونها أن الأمثال 
Faisal Masuod Muhindo

في كل مكان تعبر عن الطابع الإنساني، إذ تبلور الخبرة البشرية العامة، لذلك نجد بعض الأمثال تكاد تكون شائعة ومشتركة بين كافة الشعوب، على الرغم من تغير أسلوبها وصياغتها

ولهجتها، إلا أن المضمون يبقى واضحا في بنية المثل (ناضر، زاهي، 1992 ص 61). والمثل لم يترك في حياة الناس شيئاً إلا وله فيه قول، ونجد ذلك في الأمثال العربية والسواحلية التي تعبر عن صورة المرأة ووضعها ومكانتها، ويكمن ذلك أيضاً في تشابه الطبيعة الإنسانية، بما فيها من خير وشر، فضيلة ورذيلة، حب وكراهية، فرح وحزن، ويؤدي الانتشار الثقافي دوراً في انتقال الأمثال من مجتمع لآخر، ومن ثقافة لأخرى، فاختلاف المجتمعات والثقافات التي تعبر عنها أمثالها الشعبية المحلية، لا تحول دون وجود تشابهات تعكس صورة المرأة ووضعها ومكانتها في المجتمع. على اعتبار أن المرأة هي محور الحياة الاجتماعية داخل البيت وخارجه فإننا نجد أن لها صوراً كثيرة متقابلة في الأمثال، وكل صورة تعكس ملامحها المختلفة بحيث تختلف هذه الصور وتتنوع مع تنوع أطوار الحياة وواقعها الاجتماعي، ولهذا كان من المفيد تقصي هذه الصورة بين الأمثال العربية والأمثال السواحلية. كما يعد كشف الصورة المتعلقة بالمرأة في الأمثال العربية والأمثال السواحلية محاولة للإسهام في توضيح وضع المرأة في المجتمعات القديمة، وتخصيص ذلك في الأمثال، لأنها ربما استطاعت أن تعكس أكثر الصور واقعية عن الفكر الإنساني. ومن خلال تفصيل هذه الصورة بإيجابياتها يمكن معرفة نفسية العربي والسواحلي وقيمهم ومعتقداتهم حول المرأة، ومدى ظهور أثر الرجل في تشكيلها باتجاه سلبي أو إيجابي. منهجية البحث تعتمد هذه الدراسة على المنهج المقارن، إذ به يتم تقديم صورة الإيجابية عن المرأة من خلال الأمثال العربية والأمثال السواحلية، كما تستعين الباحث بالمنهج الوصفي التحليلي لتسليط الضوء على مضامين الأمثال ودلالتها للكشف عن صورة الإيجابية المرأة التي 
Faisal Masuod Muhindo

تعكس وضعها في المجتمع، وهذا يمكن الباحث من قيام بمقارنة صورة الإيجابية المرأة بين الأمثال العربية والأمثال السواحلية.

نتائج الدراسة وتحليلها

\section{الصور الإيجابية للمرأة في الأمثال العربية:}

ذكرت مجموعة الأمثال العربية كثير من الصفات المحمودة للمرأة، وفيها ما يعبر

عن نظرة متكافئة حظيت بها المرأة عندهم، حيث أنها نصف المجتمع التي تكمل الحياة في كل ضروبها، كما أدرك العرب أيضاً دورها الإيجابي المهم إلى جانب الرجل، وليست عارضاً ثانوياً، يستطيعون التخلي عنها أو تجاوزها، وسيظل الرجل متعلقاً بها، ولا يساوي شيئاً من دونها، ومهما حدث من كليهما، فإن الرجل سيظل رجلاً ولن يستغني عنها طوال حياته مهما عملت، ومن صورها الإيجابية ما يلي:

1- الحنون: فُطرت المرأة على الحنان حتى وُصفت النساء بالجنس اللطيف، وهذا الحنان يتبدَّى في تعاملاتها اليومية مع من حولها وكل ما حولها. لذلك يحتاج الفرد للحنان حتى وإن لم يعترف بذلك أو يطلبه. المرأة رقيقة العواطف يتجلى حنانها في كلماتها ونظراتها وصوتها وتصرفاتها، مما يلين أعماق من حولها، ويمنحهم الطمأنينة والرضا ويخفف من عنائهم، ويبعث فيهم حب الاقتراب منها، فيتعلقون بها ولا يملون من عشرتها، أو يتخلون عنها مهما حدث.

وممّا يدل على حنان المرأة قولهم: (أحنى من الوالدة)( الزمخشري، 1977 ص

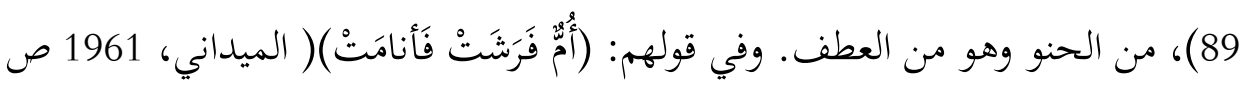
22)، تكاد تنطق الأمثال بحنان المرأة وعطفها وودها اللامنتاهي لأبنائها وغيرها. وفي استخدام صيغة أفاعل (فأنامت) ما يدل على المفاعلة والمداومة، والمفاعلة تشمل الكثير 
Faisal Masuod Muhindo

من التصرفات والعناية والمحافظة. وتخصيص الأم دون غيرها من النساء لبذلها جهدها بكل حب ورضا.

2- الخجول: ارتبطت المرأة بالحياء منذ القدم، والمرأة تبحث في هذا الخلق دائماً عن الخير حيث كان، فتتزين به ليصونها عن الابتذال ويبعدها عن مواطن الفتنة والإثارة (حسن الصفار، 2004 ص97). وكلما ازداد عمرها وعاشت تجارب الحياة، استطاعت أن توفق بينه وبين قوة الشخصية وسداد الرأي، ولذا نجد أكثر الأمثال العربية التي أشارت إلى حياء المرأة المحمود، قد ربطتها بصغيرة السن التي تكون في سن البلوغ أو قبله أو قليلة الخبرة، ومن ذلك بعض الأقوال نحو: (أحيا من كَعَاب) ( الميداني، 1961 ص 229، العسكري، 1988 ص 322)، وهي المرأَةُ حين يَبْدو ثَدَيُها للنُّهود( ابن منظور، 1997 ص 678)، فإنها فتاة صغيرة في بداية سن البلوغ. وقولهم: (أحيا من فتاة) (الميداني، 1961 ص 218)، وهي الجارية الحديثة(ابن منظور:22). وكذلك قولهم: (أحيا من بِكُر) (الميداني، 1961 ص 229، والعسكري، 1988 ص 323). والبِكُر الجارية التي لم تُفتض(ابن منظور، 1997 ص 482)، فهي صغيرة أيضاً. ويبدو في المثل الذي يقول: (أحيا من هَدِيّ) (الميداني، 1961 ص218)، "وهي المرأة التي تُهدى إلى زوجها" (الميداني: 208)، فالعروس تكون في حالة من الحياء والخجل من زوجها حتى وإن لم تكن في مقتبل العمر. وقولهم: (أحْيَا من مُخخَبَّةٍة) (الميداني، 1961 ص229؛ والعسكري، 1988 ص 323)، وهي الجاريةٌ التي في خِذْرها لم تَتَزََّج بعد (ابن منظور، 1997 ص 6)، فإنها مصانة في خدرها حتى يحين وقت زواجها. 3- الحَذِرة: جاء في الأمثال العربية صورة للمرأة الحذرة التي تحافظ على نفسها، وتتنوع أشكال المحافظة، سواء أكانت على جسدها، أم على نفسها من الآخرين، ومما يدل 
Faisal Masuod Muhindo

على الحفاظ على جسدها، المثل الذي يقول: (حَلأَتْ حالِئَّهُ عن كوِِها) (الميداني، 1961 ص 192)، فإنها تجيء فيه حذرة تدقق في إنجاز عملها حتى لا يصيبها أذى. يضرب مثلاً في حذر الإنسان على نفسه، ومدافعته عنها، وأصله في التي تحلأ الأديم، فتضعه على كوعها، ثم تسحاه بالسكين؛ فإن أخطأت قطعت كوعها. والكوع: طرف كي الزند الذي يلي الإبهام...والحلءُ: قلع اللحم عن الأديم" (العسكري 1988 ص 287). وتجد فيه انعكاساً لرؤية المجتمع العربي للمرأة أثناء عملها ودرجة إتقانها، وعظم محافظتها على يدها حتى عدوه أمراً يضرب به المثل. ومع ذلك لم يتوانَ المجتمع من أن يأمرها بالحفاظ على نفسها من الأغراب ونستدل بالمثل الذي يقول: (احفظي بيتك ممن لا تنشدين) (الزمخشري، 1977 ص 68)، وفيه: "أي ممن لا تعرفينه فتنشدينه؛ أي تطلبينه، والنشدان: الطلب، والناشد: الطالب، والمنشد المعرف"(العسكري، 1988 ص 122)، فخصص المثل بالتأنيث، مع أن مسألة التعامل مع الغريب ومن لا معرفة لك به يتساوى فيها الرجال والنساء. ويؤكد هذه النظرة، أن صورة الحذرة في المثل الأول، جاءت عن عمل تقوم به وحدها ويكون ويدويّاً، ولا تواجه فيه علاقةً خارجيةً مع الناس، ويعني ذلك أنها توضع في مرتبة القدرة على التعامل مع الأمور المعتادة والمتكررة داخل محيط بيتها، ولا تتجاوز ذلك إلى القدرة على التعاطي مع الحياة وما فيها من أحداث بشكل سليم. 4- المحبوبة: يأتي الشعور بالميل إلى الجنس الآخر نتيجة شعور فطري، فطرت المرأة كذلك على الميل إلى الرجل، وجعل هذا غريزةً فيهم وركبه فيهم تركيباً؛ بحيث يجتمع الزوجان في بيت واحد تحت سقف واحد وفي فراش واحد، ويكونان متحابين متوادين متراحمين، حتى إنهما من شدة تعلقهما ببعضهما البعض كأنهما روحٌح واحدةٌ في جسدين منفصلين . 
Faisal Masuod Muhindo

وتظهر صورة المرأة المحبوبة في المثل القائل: (أَتَيَمُ من المَرَقِِِِّ) (الميداني،1961 ص 148)، وفيه: "يعنون المرقِّشَ الأصغر، وكان متيماً بغاطمة بنت الملك المنذر، وله معها قصة طويلة، وبلغ من أمره أخيراً أن قَطَع المرقش إبهامه بأسنانه وَجْداً عليها، وفي

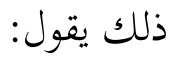

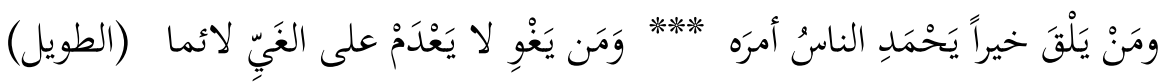

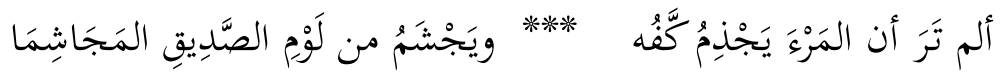
جاء من صور الحب في مثلهم: (ألْحَنُ مِنْ قَيْنَتِيْ يَزِيْدَ) ( الميداني، 1961 ص 255)، فإن يزيد بن عبد الملك يتوله في حب جاريته حبابة، حتى يوظف سلطته وماله في خدمة شوقها إلى مدينة ذكرتها في غنائها، فمجرد فكرة أو أمنية في نفسها حتى وإن كانت مستحيلةً، لا يتوانَى المحب عن تنفيذها لمحبوبته، وقد يكون المقصود أنه قادر على نقل مدينة، أكثر من قدرته على الابتعاد والفراق عنها إن هي أرادت الذهاب إلى هناك . 5- الكريمة: يعد الكرمُ قيمةً أساسيةً في حياة العرب منذ القدم؛ فقد أوجدت البيئة الصحراوية في حياتهم بعض القيم التي تساعدهم على التعايش فيها، فمن حقِّ الضيف أن يكرم ويقدم له أفضل ما عند المضيف، ولا يقتصر الأمر على الغِذاء وحده، بل يتعداه إلى حسن الوفادة والاستقبال، الذي يُظهر جانباً آخر من كرم أخلاق المضيف (محمد، توفيق أبو علي، 2001 ص 469). ومن الأمثال العربية التي تدل على كرم المرأة المثل الذي يقول: (أسْقِِ رَقاشِ إنها سَقَّاية) (الميداني، 1961 ص 333)، رَقاشِِ مثل حذام مبني على الكسر: اسم امرأة. ورقاش ليست شخصية معروفة بالكرم، وإنما هي علم على أنثى، وكأن في تعميم الاسم إشارة إلى كل النساء وكرمهن، بل في ذكر الاسم في نص المثل إظهار لإعلاء مكانتها وتقديرها، وفي تخصيصها بالسقاية من دون غيرها من أشكال الكرم زيادةً في التكريم. 
Faisal Masuod Muhindo

فالماء مصدر حياة العربي في الصحراء، والدعامة الأساسية لاستمراره فيها، فإنه يظل ينتقل من مكان لآخر خلف الماء، يحيا حيث وجد. وكان أجداد الرسول-عليه الصلاة السلام- يختصون بها للحجيج، وكان ذلك من علامات الشرف في قريش (السهيلي: 33)، ويُضْرَب المثل في الإحْسَان إلى المحسن. ويقول مثل آخر: (هو بيتي يَبْخلُ لا أنا) (الميداني، 1961 ص 92)، وفيه: "قالثه امرأة سئلت شيئاً تعذر وجوده عندها، فقيل لها: بخلتِ. ويضرب لمن شيمته الكرم غير أنه معدم(الزمخشري، 1977 ص 16). فمن شدة كرم المرأة تخجل من أن ترد سائلها، فتنسب البخل إلى بيتها تلطفاً مع السائل، وكراهية لرده بالنفي الصّريح فاستخدمت الكناية عوضاً عن التصريح، وفي ذلك إكرام للسائل بما تستطيعه من حسن الجواب. 6- المُتثِنة لعملها: تقع مسؤولية الأعمال المنزلية على المرأة وهي تستلزم الكثير من الجهد والإتقان، فتحاول الحفاظ على درجة الإجادة. وقد جاءت الأمثال العربية بصورة للمرأة الخبيرة في عملها وأمورها تتقنها، حتى يصبح ذلك مضرباً للمثل. وهي توضح نجاحها في الأعمال التي تمارسها، وإتقانها أثناء قيامها بها، حيث تدخل ضمن خصوصيات

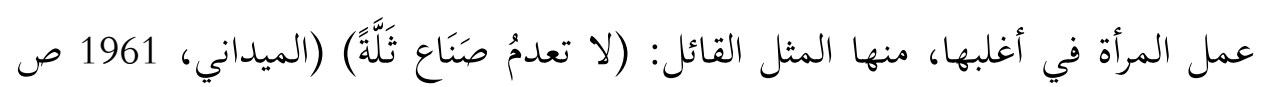
213)، وفيه: "والصَّناع: المرأة التي تعمل الثياب وغيرها، فالتي تعمل الثياب لا تعدم ثَلةً أي، صُوفاً تغزل منه" ( ، العسكري، 1988 ص 297)". ويستنبط شكل لإتقان المرأة لشؤونها الشخصية من المثل الذي يقول: (إن العوان لا تُعلَّم الخِمرة) ( الميداني، 1961 ص 19)، جاء فيه: "والعوان: الثَِّّب، وقيل: العوان بنت الثلاثين...والخمرة مثل الجلسة والقِعدة؛ أي هي عالمة بالاختمار" (العسكري،1988 ص35)". ضربت الأمثال من النساء اللاتي يحسن الإتقان ومنهن: القيان (ابن منظور، 1997 ص 431)، وقد كان الغناء فاشياً في أمهات المدن العربية قديماً 
Faisal Masuod Muhindo

(ابن عبد ربه، 1987 ص 26)، وكانت القيان حبشيات وفارسيات ويونانيات، يغنين بالعبية أو بلغاتهن الأصلية (عبد الجبار، 577) فقيل: (ألْحَنُ مِنْ جَرَادَتَيْنِ) (الميداني، 1961 ص 256)، و (أَلْحَنُ مِنْ قَيْنَتِيْ يزيدَ) ((الميداني، 1961 ص 255). وتعددت صياغات المثل فيجيء مرة: (تَرَكْتُهُ تُعَنِيهِ الجَرَادَتانِ) (الميداني، 1961 ص 131)، يضرب لمن كان لاهياً في نعمة ودَعَة، ومرة: ظَلْتَ اليومَ ثُلهيْك الجرادتان (الزمخشري، 1977 ص 155)، أي: ظلت في سرور ولهو وشرب، والجرادتان: قينتان. ومرة: صار فلان حديثَ الجرادتين (الميداني، 1961 ص 256)، فهذا التنوع في الروايات دليل شهرتيهما. ولك أن تلاحظ أن معظم أمثال الإتقان تتعلق بالمهن التي تقوم بها المرأة؛ فالحياكة وصناعة الطعام تعدان من واجبات النساء في المنزل من دون الرجال. أما الغناء، فإن من الرجال من اشتهر به، ولكن يمكن اعتبار ضرب المثل بالنساء في الغناء؛ لأنها تفوقت به، ولأنه كما يرى الجاحظ من حقها بما أن أشعار العشق والتشبيب قد قيلت فيها (الجاحظ، (1995 ص 96).

7- الذكية: تتناولت الأمثال العربية ذكاء المرأة بأكثر من طريقة، فقد تكون في صورة الفطنة، وسريعة البديهة، وربما تكون ذات قدرة عالية على الجواب والإدراك، وقد تكون ذات حكمة، ودراية بشؤون الحياة وتجاربها، أو القدرة على التعامل مع ما حباها الله به

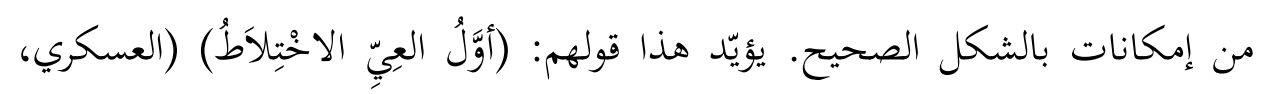
1977 ص 22)، والذي جاء ضمنه قولهم: من عجز عن الجُواب، ضحك من غير

$$
\text { عُجاب(العسكري، } 1977 \text { ص 22). }
$$

وقد يصرح في المثل بذكاء المرأة وحنكتها فيعدد أسماء مجموعة من النّساء، ويصفهن بأنهن حكيمات العرب، وهن: صُحُر بنت لقمان، وهند بنت الخُس، وجمعة بنت حابس، وابنة عامر بن الظرب الذي يقال له ذو الحلم" (الميداني، 1961 ص 37)، 
Faisal Masuod Muhindo

ويكون التصريح أيضاً بذكر أنها "ذات عقل ولسان أدبٍ وبيان"، كما في المثل الذي يقول: (ما وراءَكِك يا عِصَام؟)" (الميداني، 1961 ص 262)"، وقصة هذا المثل تجعل عصاماً امرأةً يُعتمد عليها لحسن تصرفها، وعلى ذكائها في الخطبة للملوك، فهي مبعوث الملك؛ لمعرفة خبر المرأة الجميلة التي أراد الزواج بها .

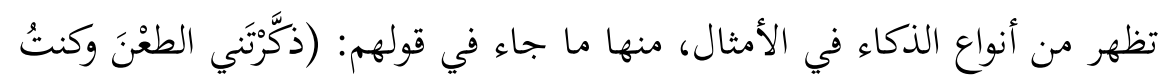
ناسِياً) (الميداني، 1961 ص 279) يضرب مثلاً للشيء ينساه الإنسان وهو مُحتاج إليه. ومثل آخر يقول: (إن العصا قُرِعَتْ لِذِي الحِلْم) (الميداني، 1961 ص 373). ويلحق بذكاء الذهن والفطنة إصدار الحِكَم، التي تخرج من عصارة خبرة في الحياة وخوض لدروبها وفهم لخفاياها فهي مما يؤكد على العقل والاستفادة من التجارب التي يمر بها الإنسان(ابن الجوزي، 13)، ونجد نحواً من ذلك في مثلين: (لا جَدِيد لمن لا خلق لَه) (الميداني، 1961: 231)، و (ملكت فأسجح) (الميداني، 1961 ص 283). 8- الحليمة: يظهر الحلم عند المرأة في قصة المثل الذي يقول: (أبْطَأُ مِنْ فِنْدِ) (الميداني،

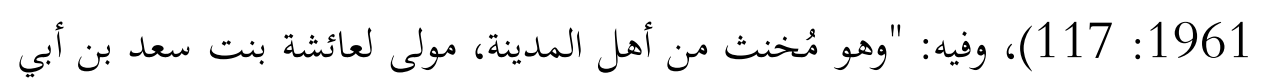
وقاص، بعثته ليقتبس ناراً، فأتى مصر، وأقام بها سنة، ثم جاءها بنار يعدو، فتبدد الجَمْر،

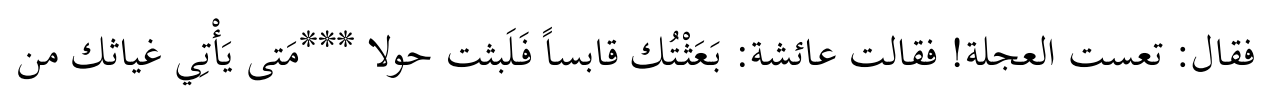

$$
\text { تُغنيث (السكري، 1988: 203) }
$$

فهنا لم تغضب كما كان متوقعاً في مثل تلك الموقف، بل اكتفت بأن صفحت عنه وحولت غضبها إلى بيت من الشعر، تتعجب فيه من تصرفه. وتعد تلك درجة عالية من الحلم، فقد "قيل لقيس بن عاصم: ما الحلم؟ قال: أن تصل من قطعك وتعطي من حرمك وتعفو عمن ظلمك"((ابن عبد ربه، 123). فعفوها عنه مع ظلمه لها غاية الحلم. 
Faisal Masuod Muhindo

ومما يستنبط من تأكيد لرؤية خاصة حول المرأة ودرجة ضبطها لمشاعرها قولهم: (أحلم من فرخ العقاب) (الميداني، 1961 ص 220)، وَذَلِكَ أَنه يخرج من الْبَيْضَة على

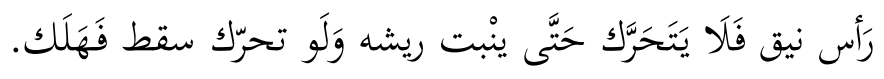

9- الثجاعة/ القوية: يعد شعور الإنسان بمكانته ومعرفته بحقيقة نفسه وشعوره، وبما له من حقوق وما عليه من واجبات، هو العزة التي أظهرتها الأمثال العبية عند بعض النساء. ظهرت في مجموعة من الأمثال حول شخصيتين رئيستين هما: الزبََّّاء ملكة تدمر، وحليمة ابنة الحارث بن أبى شمر، ملك الشام. وهما من ذوات الثّأن والرّفعة، وليستا من العامة، وقد صرحت الأمثال بعزتيهما وشجاعتهما فقيل: (أَعَنُّ منَ الزَّبّاء) (الميداني، 1961 ص 43)، وقولهم: (أَعَزُّهنْ مِليمةً) (الميداني، 1961 ص 45). وهي بنت الحارث بن أبي شمر الغساني الأعرج ملك الشام، وهي التي أضيف إليها اليوم، فقيل: (ما يَوُُْ حليمة بِسِرِّ)، وذلك أن المنذر بن المنذر بن ماء السماء سار إلى الحارث بعرب العراق لقتاله، فخرجت هي محضضةً لعسكر أبيها وطيبهم بعطر أخرجته لهم في مراكن (ابن منظور، د.ت ص226)، وهو أشهر أيام العرب، يزعمون أن الغبار ارتفع حتى سد عين الشمس، فظهرت الكواكب وقتل المنذر وكان ملك العراق(الزخشري، 1977 ص 246)، وقد تعددت الروايات فيه أيضاً، وتعدت صيغ المثل فقيل: (ما يوم حليمة لبر) (الميداني، 1961 ص 272)، و(ما يوم حليمة بِسِرِّ) (الزمخشري، 1977 ص 246/1). يتغير في الروايات الأخرى موقف حليمة ما بين العزة والذلة .

ومن مظاهر شجاعتها وقوتها في الرواية السابقة خروجها للحرب مع أبيها وحثها الجنود على القتال، وهو أمر يبدو طبيعيّاً في حياة العرب، كما أن تطيبها لهم بنفسها قوَّى من عزيمتهم، وجعلهم يستبسلون في الدفاع، فإنها شكلت لديهم الحِمى الذي يذودون عنه. 
Faisal Masuod Muhindo

\section{الصور الإيجابية للمرأة في الأمثال السواحلية:}

ذكرت بعض الأمثال السواحلية كثيراً من الصفات الإيجابية للمرأة، منها بواسطة الظواهر

والصفات الآتية:

1. الحنون: لا يوجد في الحياة امرأة واحدة تهب كل حياتها وكل عمرها من دون أن تنتظر مقابلاً إلا الأم، وليست في العالم وسادة أنعم من خضن الأم. وحنانها يكون على الصغير والضعيف، وبخاصة الأبناء، يعبّر عن هذا المعنى قولهم: Huruma ya mama/ hakuna mwema kama mama ماما..أي، لا مثيل للأم في الحنان)، يجري هذه الجمل مجرى الأمثال، يقود الرجلٌ المرأةَ في كل شيء إلا السعادة والحب والحنان فالأم هي من تقوده إليه!. الحنان هو مفتاح شخصية المرأة، وأفضل الزوجات هي الزوج الحنون، ويؤيد هذا المثل القائل:kwenye uvuli ndipo niwekapo mwanagu (كوني أُقول نديو نوكابو مُوَنَو..أي، أضع ولدي في المكان الذي فيه الظل)، وهى الأم الحنون التى تحتضن طفلها وتزيل عنه آلام ومتاعب الحياة. يظهر حنان الأم النفسي في عاطفتها تجاه أبنائها وحرصها على سعادتهم، إذ تسهم في المحافظة على أبنائها، تنام مع ولدها منذ صغره بكل أحاسيسها، وتساعده في كل وعكة يقع فيها، وعبّر عن ذلك المثل القائل: mama hawezi kumkana mtoto hata akiwa na vilema (ماما هويز كمْكنَ متوتو هت أكون نَ ثيبليمآ..أي، لا تستطيع الأم أن ترفض ولدها وحتى وإن كان معاقاً ) م

2. الخجول: المرأة في الحقيقة قطعة من الحياء، فإذا فقدت المرأة حياءها فقد كلَّ شيء6 وفعلت كلَّ شيء. وارتبط خلق الحياء بالمرأة منذ القدم، وأوصى به الدين الإسلامي الحنيف. ولذا نجد أكثر الأمثال التي إشارت إلى حياء المرأة المحمود، قد ربطتها بكل 
Faisal Masuod Muhindo

امرأة صغيرة السن كانت أو كبيرة السن، ومن ذلك بعض الأقوال التي جرت مجرى المثل على النحو:ana haya kama za mwanamke (أنا هيا كما ز موانمك..أي، أحيا كالمرأة).

وكذلك قال السواحليون في أمثالها: Chanda [kidole] chema huvishwa

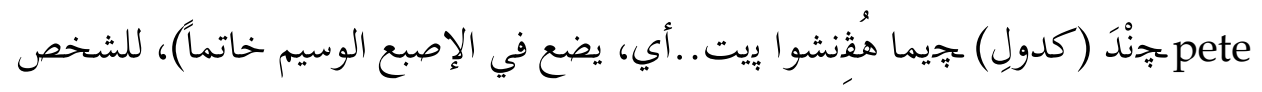
الذي يستحق التقدير أن يحصل على عذراء جميلة. ويستخدم هذا المثل لإظهار هذا

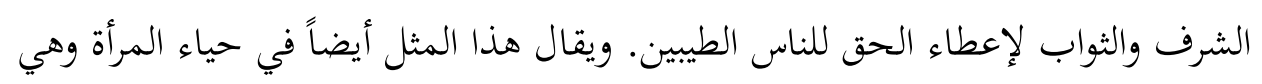

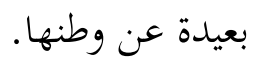
ويضبط الحياء سلوك المرأة التي تحب أن تكون لها مكانةً مميزةً، وما نستدل به وطها

على ذلك المثل القائل: Haya imemaliza shamba langu la muhindi (هيا

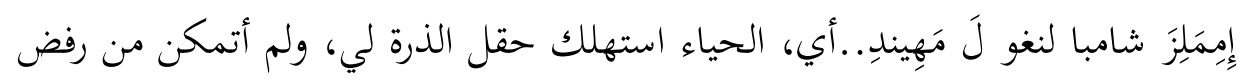
أي طلب)، وقولهم: Johari za mtu ni mbili--akili na haya (بُهارِ ز متو نِ لنِ مبيل أكِِل نَهياً. أي، أفضل الصفات للشخص اثنان -الذكاء والحياء-) فالمرأة لابد أن تتصف بالأخلاق الحميدة؛ لأن جمالها ليس في صورتها فقط بل في أخلاقها وأدبها.

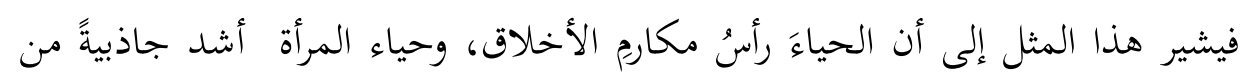

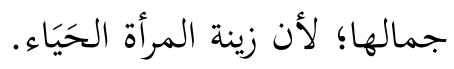

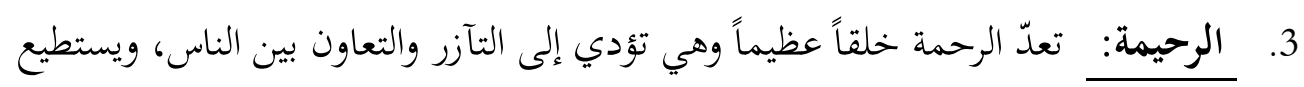
الإنسان أن يعلم قيمة خلق الرحمة في المرأة ومنزلته من خلال النظر في دورها في بناء الرداء

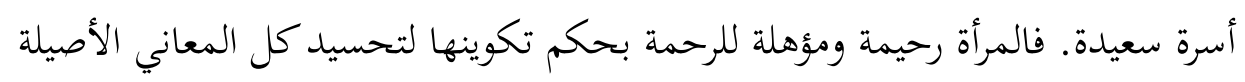

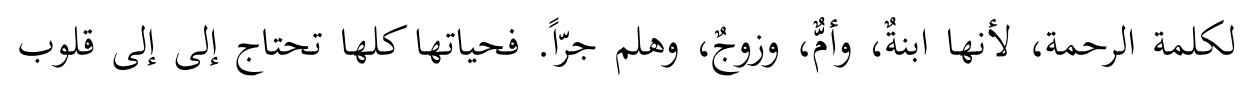

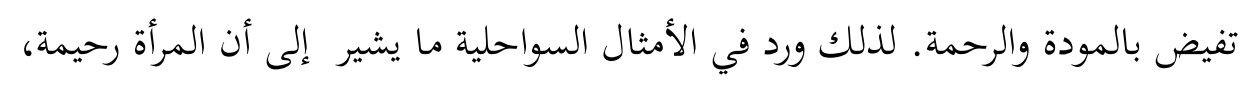


Faisal Masuod Muhindo

ومن أقوالهم التي تدل على رحمة المرأة من دون التصريح المثل القائل: Mama na mama, huona huruma أم أخرى)؛ لأنها تعرف معاناتها (معاناة بعضهن لبعض). والمثل الذي يقول: mama hawezi kumkana mtoto hata akiwa na vilema هت أكون نَ ثيليدآ..أي، الأم لا يمكنها أن تنبذ طفلها، حتى لو كانت لديها عيوباً)، ومن ذلك أيضاً: azaaye kingog akinyonyeshe (أَزأي كِنغوغُ أَكِنْيُونيوشو..أي، التي تضع طفلاً مشوهاً ترضعه) وقد يقصد به: (الأم لا تترك طفلها حتى لو كان مشوهاً)، فترحم طفلها وتقوم بتربيته على الرغم مما به من الإعاقة والأذى.

4. الحافظة: ورد في بعض الأمثال السواحلية صورة للمرأة التي تحافظ على نفسها، وتنوعت أشكال المحافظة، سواءً أكانت على جسدها أم على نفسها من الآخرين، وما نستشهد به في الحفاظ على جسدها المثل القائل: hautamkuta mwanamke anaye jidharau فتجيء حذرة تدقق في إنجاز عملها حتى لا يصيبها أذى. فتتغير نظرة المجتمع السواحلي للمرأة أثناء عملها ودرجة إتقانها. ونجد ذلك أيضاً في قولهم: mwana akinyea kiweo akikatwi دبره)، بل تنظف وترمى الأقذار في مكانها المناسب. تقوم المرأة بتنظف طفلها حفاظاً على صحة الطفل وصحة الآخرين.

وتحرص المرأة غالباً في مرحلة عقد القران لتكون الأجمل والأبهى في عين الخاطب، وتعمد إلى استخدام زينتها كوسيلة من وسائل لفت الانتباه، وتسعى إلى أسر قلبه، وتقييد هواه بكل ما استطاعت من وسائل الزينة. وربما المنهي عنه في قولهم: Mwanamume ni mbono, hualikia kule 
Faisal Masuod Muhindo

الزوج حشرة زحافة، يمتد بعيداً)، للتأكيد على تحذيرها وزيادة في توجيهـا إلى الاهتمام بجمالها خصوصاً أمام زوجها. 5. المحبوبة: يرغب الرجل دائماً أن يرى صفات معيّنة في شريكة حياته، وفي كلّ من يحب، كابنته وأمه وأخته، مما يجعل من علاقتهم علاقة مميّزةً، ومتجدِّدةً، ومتوازنةً. إن حب المرأة قضاء محتوم على الرجل، فالهوى يأسره ويسيطر على تفكيره حتى لا يكون له فكاك منه ولا معصم؛ لأنه زُيّن للنّاس محبة ما يشتهون من النّساء. يميل الرجل إلى لى المرأة وتميل المرأة إلى الرجل، وجعل هذا الميل سبباً لتحقيق السّعادة في الدّين والدّنيا، بحيث يتم حصول السكينة، والطمأنينة، والرحمة، والود العميق بين الأبوين وأولادهم، وبين الزوجين، فجمع الله جلّ شانه الرجل والمرأة في رباط عظيم، وفي ميثاق غليظ حتى تنطلق هذه الفطرة انطلاقتها الرحيبة، ويوضح هذا الأمر المثل القائل: Mahaba yana mkono wake وقته الخاص، ومثل آخر يقول: Mapenzi hayana macho, wala hayana (مديبز هَيَنا ماشو ولا هيناً مأرِفَ. .أي، ليس للحب عيون ولا فهم/ ليس للحب مشورة)؛ لأن الحب من أمتع المشاعر التي تصيب الإنسان -ذكراً كان أم أنثى - حتى وإن كان مؤلماً فهو الألم اللذيذ؛ ولأنه عندما يحب لا يرى عيوب الحبيب فيمشي بأعين مغلقة.

ومن صور الحب ما جاء في قولهم: Mimi na wewe pete na kidole (ميمي نَ ويوي بِيتي نَكِدُولي ..أي، أنا وأنت -في الحب وتضحية النفس - مثل الخاتم في الإصبع)، فإن الرجل يتوله في حب امرأة شغفاً حتى يوظف سلطته وماله في خدمة عشقها، كما لا يترك الخاتم الإصبع، وهو كذلك سيحبها إلى نهاية حياته. وهناك مثل

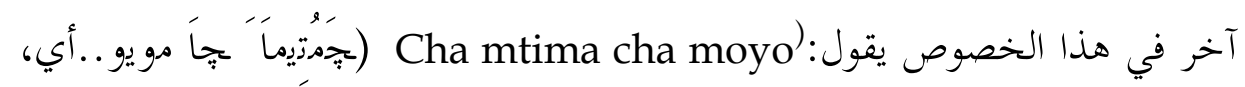


Faisal Masuod Muhindo

القلب يحب ما تريد/ ما يحبه القلب هو ما تريده- جيده، أو سيئة)، فيكون للقلب مثل الدواء. وغيرها من الأمثال عن الحب. ترجع فكرة الحب المذكورة في الأمثال السابقة إلى محبة الرجل للمرأة، والعكس صحيح في بعضها، والغالب يخص الرجال أكثر من النساء. فتكون المرأة محبوبةً لدي الرجل ويعمل كل ما في وسعه للحصول عليها، وإظهار محبته لها.

6. الكريمة: يعدّ الكرم فضيلة مقبولة بصفة كبيرة في المجتمع السواحلي وخلة مرغوب فيها، فمن حق الضيف أن يُكرم، ويُقدم له أفضل ما عند المضيف، ولا يقتصر الأمر على الغِذاء وحده، بل يتعداه إلى حسن الوفادة، والاستقبال الذي يُظهر جانباً آخر من كرم أخلاق المضيف.

تدلّ بعض الأمثال السّواحلية على كرم الضيافة، منها المثل القائل: Njoo

mgeni uponye mwenye nyumba / رحب بالضيف، واحفظ المضيف). ومما يحث على حسن الترحيب بالضيف، وحفاوة الاستقبال، وكرم الضيافة، قولهم: كhereheka na mgeni wako kama vile (شريهيك نَ مُغين وككم ambavyo ungependa ushereheshwa ugenini ثَيل أُغِندا أُشِهِشُُوَ أُنغنينين..أي، كن كريماً للضيف كما تريد أن يكون شخصاً كريماً معك/ اكرم الضيف كما تريد أن تُكرم). وتعدّ الضيافة، وتقديم الطعام، والصداقة، والحب، صفات منتشرة بين السواحليين، حيث يقومون بتقديم الطعام للضيف من دون سؤال عن رغبته في الأكل، ومن عاداتهم عدم السؤال عن الأطعمة المفضلة والمشروبات لدي الضيف (iringaliving.co.tz، وما نستشهد به على حسن معاملة الضيف ما جاء في المثل القائل: Mwenye kuwa na mgeni haoni mwezi mwandamo 
Faisal Masuod Muhindo

موندمو...أي، المضيف لا يرى الهلال)، بمعني: يجب على المضيف عدم تنبيه الزائر

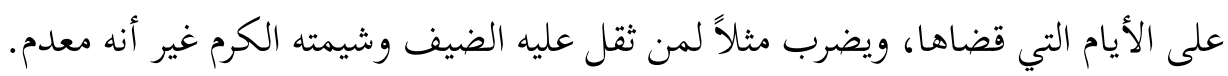

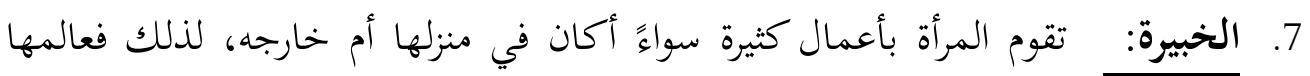

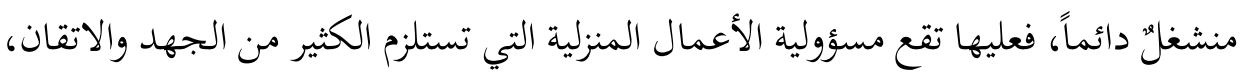

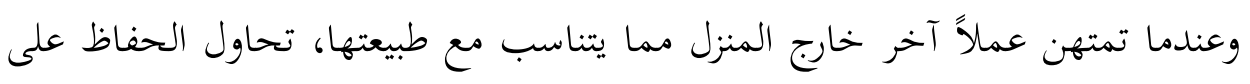
درجة خاصة من الإجادة. ومما يعبّر عن ذلك قولهم: mwanamke hufanya kazi zote wanaume hufurahi

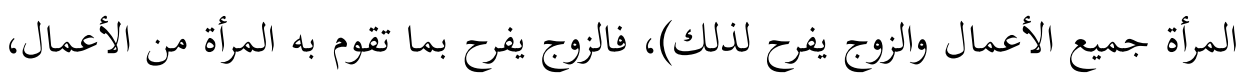

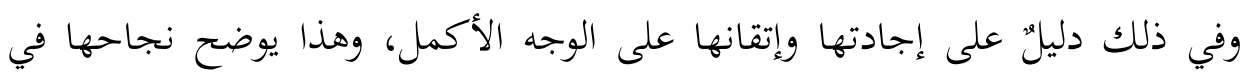
الأعمال التي تمارسها وتدخل ضمن خصوصيات عمل المرأة غالباً. ويوضح أعمال المرأة اللانهائية المثل القائل: mwenye kuleya hana ngoya

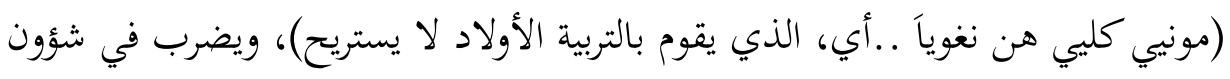

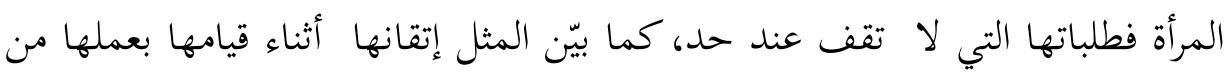

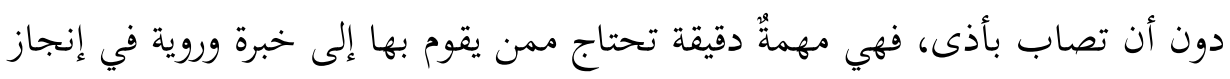

العمل. وجاء في قولهم: Sahani ukifunika kili chomo husitirika

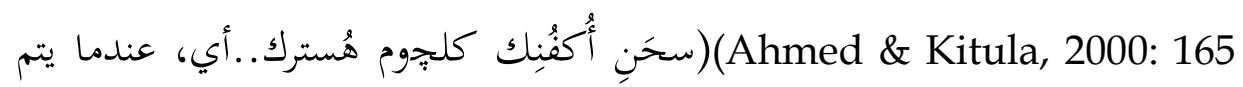
تغطية لوحة، يتم إخفاء محتوياتها)، إشارة لإتقان المرأة لشؤونها الشخصية.

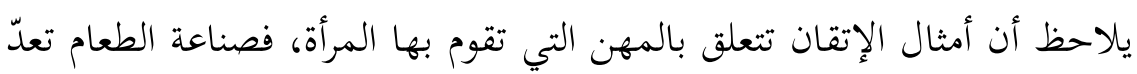

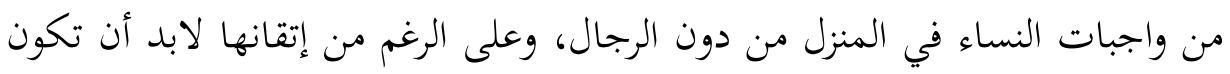
بها نقيصة. يقول المثل في هذا الشأن: ugali nitepete hata alipika maama

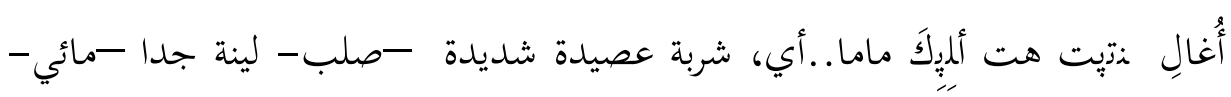


Faisal Masuod Muhindo

وإن كانت الأم هي التي طبختها). يشير إلى غلط في الطبّخ، حيث لم تطبخ جيداً، وصار نوعية الطبخ معيوبة. وإن بلغت الإتقان في عملها فإنها لابد أن يعاب منها شيء آخر أو نقص فيما قامت به هي.

احتوت الصفات المحمودة للمرأة في الأمثال السواحلية عموماً على العديد من

الأوجه، ونالت فيها تقديراً واحتراماً، سواءً كان التقدير لمميزاتها العقلية، كما هي في الخبرة، أو قدراتها المهارية، كما هي في المحافظة على شرفها، أو صفاتها الخُلقية، كونها حيية، أو النفسية، وكونها محبوبة.

صور المرأة المشتركة بين المجتمعين:

من صور المرأة الإيجابية المشتركة بين المجتمعين: المرأة الحنون، والخجول، والمحبوبة، والكريمة.

الأمثال العربية والسواحيلية المتشابهة

هناك أمثال سواحلية تحمل معانيَ تتطابقُ مع معاني أمثال عربية مشهورة، وهي على

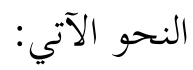

1- - يقول المثل السواحلي: (هكُون مويما كما ماما)، وهذا يقابل في الأمثال العببية قولهم:

$$
\text { (أحنى من الوالدة) (الميداني، } 1961 \text { ص 89). }
$$

2- يقول المثل السواحلي: (كوني أُفول ندِيو نوكابو مُوَنغو)، وهذا يقابل في الأمثال العربية قولهم: (أم فرشت فانامت) (الميداني، 1961 ص 22).

3- وجاء في المثل السواحلي: (أسِشيلويش كازر ي لووُ كُعِفَنَيًا كشو)، وهذا يقابل في الأمثال العربية قولهم: ( لاََتُؤخِّرْ عَمَلَ اليَوْمر لِغَدِ). 
Faisal Masuod Muhindo

4- يقول المثل السواحلي: (هكونَ مكِيكَ مُوُنغُوَن)، ويقابله في الأمثال العربية قولهم:

$$
\text { (أحرق من أمة). }
$$

5- يقول المثل السواحلي: (موانمك هَرِضِك أَبَدنْ)، وهذا يقابل عند العرب مثلهم القائل:

$$
\text { (أكفر من ناشزة). }
$$

6- يقول المثل السواحلي: (هَكُون أَنَيمشيندَا موانأم كما موانمك)، وهذا يشبه في الأمثال

$$
\begin{aligned}
& \text { العربية قولهم: (النّبَاءُ حَبَائلُ الشََّّْطانِ) (الميداني، } 1961 \text { ص 340). } \\
& \text { أمثال متقاربة في المعنى: - 2 }
\end{aligned}
$$

توجد أمثال سواحلية تقرب معانيها من معاني أمثال عربية معروفة، ولكنها لا تتطابق معها

على النحو الذي رأيناه في الأمثال المذكورة أعلاه، منها:

1- يقول المثل السواحلي: (تِيت لَ ماما لِتَمو هَاتَ لِكِوا امبوا)، يقرب من قول العرب:

$$
\text { (الطفل الذي لم ترضعه أمه سوف تمتص حتى الثدى العاهرة). }
$$

2- - يقول المثل السواحلي: (مغين نِ ماجي ينفُو)، فيه صديً لقول العرب: (أسْقِق رَقاشِ إنها

$$
\text { سَقَّاية) (الميداني، } 1961 \text { ص 333). }
$$

3- يقول المثل السواحلي: (كنْبَما إِكِكَتِكَ توؤنغني انغينيي)، وهذا يقرب من معنى قولهم:

$$
\text { (لا مَخْبَاً لِعِطرٍٍ بَعْدَ عَرُوسِ) (الميداني، } 1961 \text { ص 211). }
$$

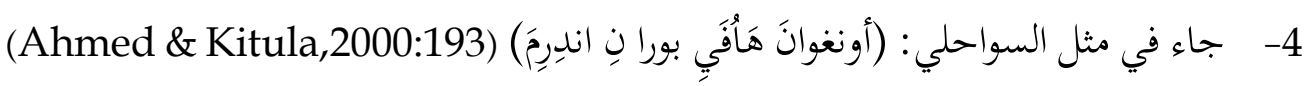

$$
\text { يُشبه -إلى حدِّ ما- قول العرب: (لا يعيب الرجل إلا جيبه). }
$$

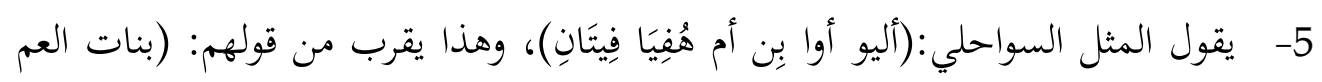

$$
\text { أحسن مواساة) (الزمخشري، } 1412 \text { ص 247). }
$$

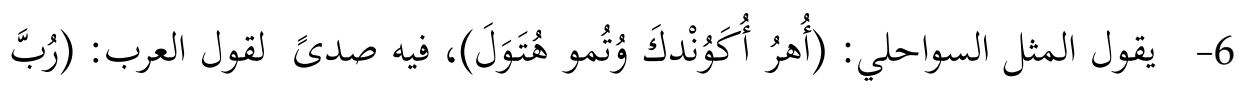

$$
\text { عَجَلَةٍ تَهَبُ رَيْناً) (الميداني، } 1961 \text { ص 294). }
$$


Faisal Masuod Muhindo

7- جاء في المثل السواحلي: (باب بِ باب لَؤ كما نِكَهَبَ)، فيه شيءٌ من قولهم: (عَذَرَتِنْي

$$
\text { كلهُ ذَاتِ أبٍ) (الميداني، } 1961 \text { ص 34). }
$$

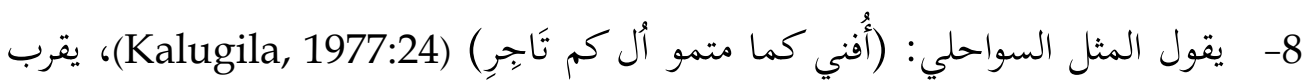

$$
\text { من معنى قولهم: (أمَامَها تَلْقَى أَََّةٌ عَمَلَها) (الميداني، } 1961 \text { ص 20). }
$$

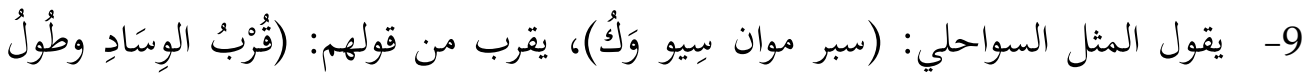

$$
\text { السِّوادِ) (الميداني، } 1961 \text { ص 93). }
$$

10- وجاء في المثل السواحلي: (كلَ أَشَرَتِ هنَ مَزوُوِي)، وهذا يقرب من قولهم: (تَنْهَانَا أُمْنَا

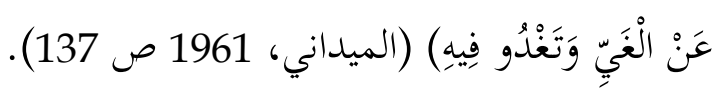

11- يقول المثل السواحلي: (نشَانْدَ (كدولِ) نشيما هُفِنشو بيتِ) Ahmed \& Kitula, (2000:9 يشبه في الأمثال العربية قولهم: (إن المنَاكِحَ خَيرهَا الأبْكارُ) (الميداني، 1961

12- وجاء في المثل السواحلي:( هِي يَفُتِكَكَ هِي هَيْفتِكِك)، يقرب من معنى المثل العربي:

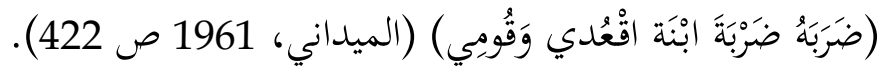

13- يقول المثل السواحلي: (هير يكُُ هير يانغو)، وفي هذا صديًُ من قولهم: (لَا جَدِيد لمن

$$
\text { لَا خلق لَهُ) (المداني، } 1961 \text { ص231). }
$$

14- وجاء في المثل السواحلي: (هَتَ متُمُوَا أَلْبَتَ كُوَ متوتو و مُوتُ)، يقرب في معناه من

$$
\text { معنى قولهم: (عَبْدُ غَيْرِكَ حُرِّرُِّْْلكَ) (الميداني، } 1961 \text { ص 5). }
$$

وبالإضافة إلى هذين النوعين من الأمثال السواحلية، توجد أمثال سواحلية عديدة لا نكاد نجد ما يقابلها في الأمثال العربية، ولا نجد ما يقرب من معانيها، وقد ورد ذكر كثير منها في هذه الورقة. - مذا

الخلاصة والتوصيات 
Faisal Masuod Muhindo

من أهم ما توصلت إليه نتائج الدراسة ما يلي:

إن الأمثال في اللغتين المتعلقة بصورة المرأة ووضعها ومكانتها تكمن في تشابه الطبيعية

$$
\text { الإنسانية بما فيها من خير وشر، فضيلة ورذيلة حب وكراهية فرح وحزن. }
$$

خيانة الزوجة كانت السمة الأكثر ظهوراً لها في الأمثال العربية والسواحلية، وهذا لا ينفي الصورة الجيدة للزوجة الوفية، ولكن الغالب خيانتها، وعندما يريد إعلاء قدرتها يحولها إلى مرتبة الأمومة لتكون في مكانة أعلى من الزوجة.

أسهبت الأمثال العربية في وصف المرأة وفي توجيهها أكثر من الأمثال السواحلية

$$
\text { وبخاصة ما جاء في أهم كتاب للأمثال -مجمع الأمثال للميداني.- }
$$

تبقى علاقة الرجل بالمرأة علاقة ود وتعاون برغم ما احتوته الأمثال العربية والسواحلية من صور السلبية للمرأة؛ لأن الأمثال في اللغتين للتوجيه الاجتماعي، وللوقاية مما يمكن

$$
\text { أن يقع من أخطاء أو أخطار. }
$$

$$
\text { توصيات البحث: }
$$

$$
\text { في ضوء تنائج البحث، أوصى الباجث بما يلي : }
$$

أولا: إدخال بعض عناصر التراث العربي والإفريقي خاصة ما يتعلق بالمرأة في المناهج التعليمية، وتضمينها بصورة إيجابية للمرأة من خلال الأدوار المختلفة التي تقوم بها المرأة المرأة. ثانيا: تحقيق كتب الأمثال السواحلية الموجودة تحقيقاً علميّاً حديثاً فالباحثون والمثقفون بحاجة إلى نسخ علمية محققة للكتب الأمثال في اللغة السواحلية. ثالثا: جمع الأمثال السواحلية وشرحها شرحاً وافياً، ودراسة الأمثال السواحلية التي خرجت على القياس اللغوي، وبيان قياسها الصحيح. 
Faisal Masuod Muhindo

\section{المصادر والمراجع}

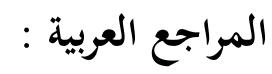

ابن منظور، محمد بن مكرم بن علي، (1997). لسان العرب، دار صادر، بيروت-لبنان

الأصبهاني، حمزة بن الحسن، (2009). الأمثال الصادرة عن بيوت الشعر، تحقيق: أحمد الطبيب، دار المدار اللبناني .

الأصبهاني، حمزة بن الحسن( د.ت.ط). الدرة الفاخرة في الأمثال السائرة، تحقيق: د.عبد المجيد قطامش، دار المعرف بمصر .

الأندلسي، أحمد بن محمد بن عبد ربه، (1987). العقد الفريد، تحقيق: د/مفيد قميحة،

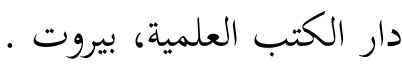

البكري، أبو عبد الله عبد الله بن عبد العزيز بن محمد بن أيوب الأونبي، (1983). فصل

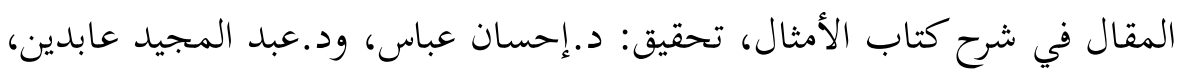

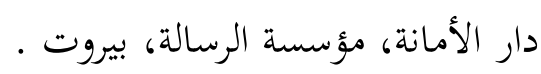

الزمخشري، أبو القاسم، محمود بن عمرو بن أحمد، (1977). المستقصى في أمثال العرب، دار الكتب العلمية، بيروت-لبنان .

السامرائي، إبراهيم، (1977). اللغة والحضارة، المؤسسة العربية للدراسات والنشر، بيروت . الضبي، المفضل بن محمد بن يعلى بن سالم، (1983). أمثال العرب، تحقيق: إحسان عباس،

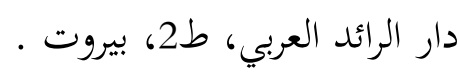

العسكري، أبو الهلال، الحسن بن سهل، (1988م). جمهرة الأمثال، ضبط: د.أحمد عبد السلام، خرّج أحاديثه: أبو هاجر سعيد بسيوني زغلول، دار الكتب العلمية، بيروت . القاسم بن سلام أبو عبيد، (1980). كتاب الأمثال، تحقيق: د.عبد المجيد قطامش، دار 
Faisal Masuod Muhindo

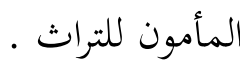

الميداني، أبو الفضل، (1961). أحمد بن محمد، مجمع الأمثال، دار مكتبة الحياة، بيروت.

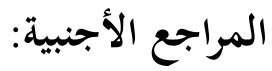

Ahmed Ndalu na Kitula G. Kinge'I, (2000). Kamusi ya Methali za Kiswahili, East African Educational Publishers, Nairobi - Kenya.

Claudia Dal Bianco na Johana Emig, (2009). Diwani ya Methali, Taasisi ya Taaluma ya Bara La Afrika Chuo Kikuu cha Vienna, Vien

Leonidas Kalugila, (1977). Methali za Kiswahili kutoka Afrika Mashariki, Scandanavian Institute of African Studies, Uppsala.

Uchunguzi wa Kiswahili, (TUKI), (1981). Kamusi ya Kiswahili Sanifu, Oxford University Press, E.A, Nairobi- Kenya

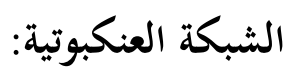

http:/ / swahiliproverbs.afrst.illinois.edu/index.htm

http://www.goswahili.org/dictionary/ 
Faisal Masuod Muhindo

This Page Is Intentionally Left Blank

تركت هذه الصفحة فارغة عمدا

'Halaman Ini Sengaja Dikosongkan' 